\title{
THE SPATIAL ANALYSIS OF HEAT WAVES IN SOUTH EAST OF IRAN A CASE STUDY: SISTAN AND BALUCHESTAN PROVINCE
}

\author{
Morteza ESMAILNEJAD ${ }^{I}$
}

DOI: 10.21163/GT_2016.112.05

\begin{abstract}
:
This study describes the main characteristics of a heat wave that occurred over Sistan and Baluchestan. Province located in the south east of Iran. First, we analyzed daily maximum temperature (DMT) recorded at 12 stations during 1961-2015, in southern of Iran. Then geographical patterns of heat waves (HWs), including those persisting for 2-5 days and longer over this province were studied. To indicate heat waves we used the value of the 90th percentile of the annual maximum temperature distribution at a station an then heat wave (HWs) is defined as the maximum number of consecutive days where the daily maximum temperature the long-term daily 90th percentile. Our analysis showed that Two poles of high frequencies (over 2 days per year) of the HWs during April-October were found in the regions of Jazmourian plain and the northern areas of SB. HWs increased significantly during the studied period in most regions of the province, especially over the northwestern areas and the west Sistan and Baluchestan. Increasing trend of HWs occurred after the 2005s in all regions, especially in northern SB and the southeastern coastal.
\end{abstract}

Key-words: Iran, Sistan and Baluchestan, Heat waves, Trend.

\section{INTRODUCTION}

The rapid buildup of greenhouse gases is expected to increase both mean temperature and temperature variability around the world (Schar et al., 2004). Extreme weather situations produce strong impacts on humankind activities (Easterling et al., 2000). Heat waves are periods of unusually hot weather that affect human health through heat stress and exacerbate underlying conditions, such as cardiovascular, cerebrovascular, and respiratory diseases (Kyselý, 2004; Ebi \& Meehl, 2007). Anthropogenic climate change brings with it an expected increase in the frequency of heat waves (McCarthy et al., 2001) Heat waves are believed to become more frequent, more intense and longer lasting with climate change (Huth, Kysely \& Pokorna 2000; Stott, Stone \& Allen 2004) Moreover, some studies have documented an increase in the average frequency of heat waves of 0.24 per decade since 1880 (Della-Marta et al., 2007). But relatively little is known about the climatic behavior of heat waves. Heat waves and climate events have wide ranging impacts on human activates and society as well as on biophysical systems and heat island effect (McGregor al., 2005; Hassid et al., 2000; Changnon, Kunkel \& Reinke, 1996; Goklany, 2008; Palecki, Changnon \& Kunkel, 2001). Everyone agrees on the gravity of the effects of a heat wave on human health and mortality and also the damage to agriculture, forests and water resources. It could be considered as the major cause of weather-related fatalities (Robinson, 2001) in recent years, intense heat waves affect many place Over the world, Warm days increased by 2.18 days/decade for the Northern Hemisphere during 1948-2006 (Fang et al., 2008). Heat

\footnotetext{
${ }^{1}$ Department of Geography, University of Birjand, Avini Bul,Birjand, Iran, Esmailnejad.m@birjand.ac.ir
} 
phenomena such as that of the summer in 2003 are thus expected to become more common in the near future (Meehl \& Tebaldi, 2004). In addition, future climate scenarios suggest that in a 'warmer world' heat vulnerability may increase significantly (McGeehin \& Mirabelli, 2001).According to the European 2003 Heat Wave Project (Robine and et al. 2008)supported by the European Union, more than 70,000 additional deaths were recorded in 2003 in twelve countries in Europe. In France and Italy, mortality reached respectively 19490 and 20089 deaths (Robine et al., 2008). Extreme temperature in 2003, European heat wave have an unprecedented impact on our Society and economy (Kovats \& Koppe, 2005). Heat wave, is a more considerable aspect of climate change. According to IPCC, (2007) reports heat events will be more severety and more frequency over the century in Iran. Regional climate features and changes of hot and cold days are remarkable in Iran under global Warming. There is a lot of public concern about possible increase in the frequency of heat waves events under global warming, in southern of Iran, because they may exert a greater impact on human health, water resources and agriculture. New record of temperatures in recent years have been recorded in southern Iran. In the Sistan and Baluchestan Province (Fig. 1) several hundred people lost their lives during the heat waves. Heat waves and hot spot are the focus of this study.

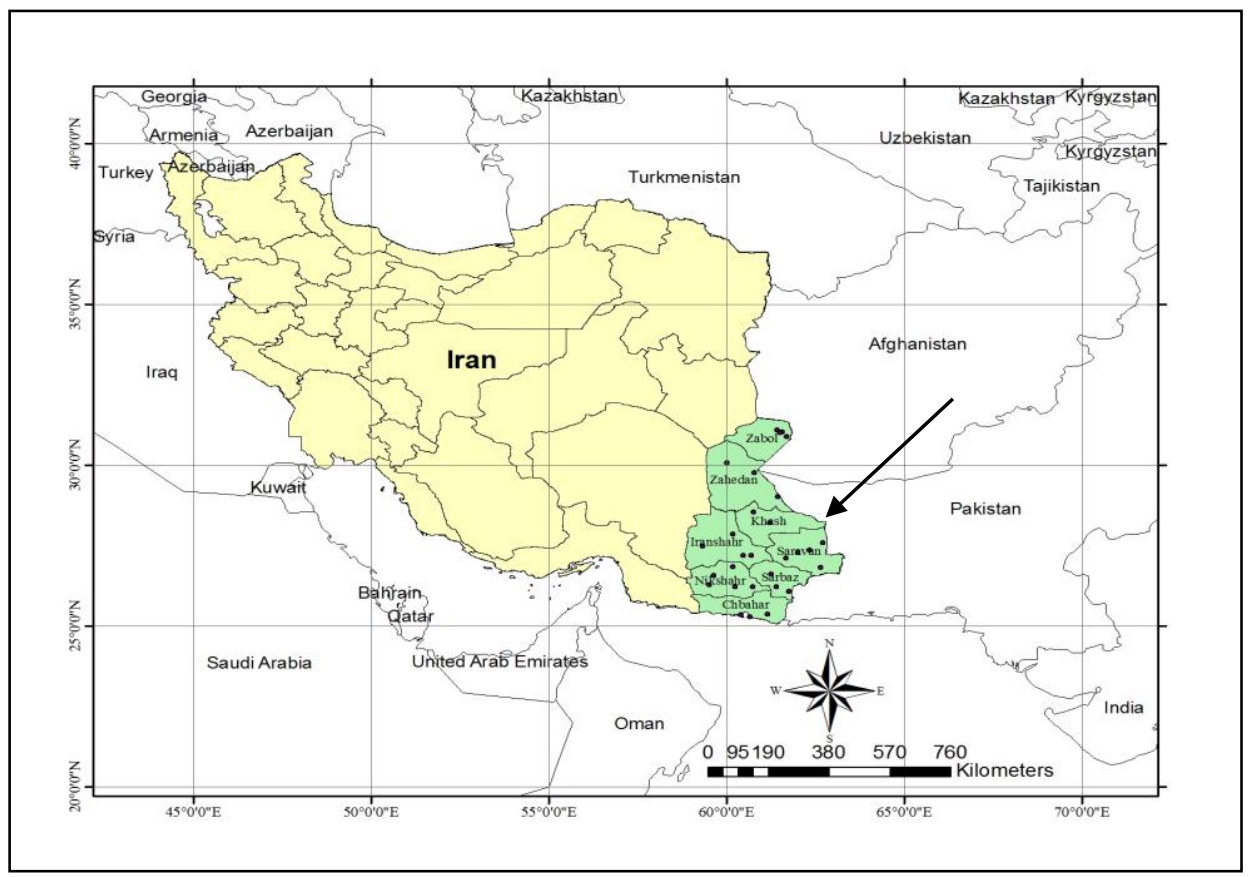

Fig. 1. Location of Sistan and Baluchestan.

\section{DATA AND METHODS}

\subsection{Data}

The aim of this work is to study heat waves (HWs) in Sistan and Baluchestan(SB) of Iran, Because numerous deaths have been reported in this region, caused by heatstroke. Daily maximum temperature (DMT) recorded for the period 1961-2014 (53 years) were 
furnished by the Iran Meteorology organization (IRMO), these data covering 12 stations (Table 1). The stations are evenly distributed in the SB, but scarce in the South west of SB.

Table 1. Station locations

\begin{tabular}{|l|c|c|c|}
\hline Station & Latitude & Longitude & Elevation(M) \\
\hline Zahak & 61.7 & 30.9 & 495 \\
\hline Konarak & 60.4 & 25.4 & 12 \\
\hline Zabol & 61.2 & 31.2 & 498 \\
\hline Khash & 61.2 & 28.2 & 1394 \\
\hline Iranshar & 60.7 & 27.2 & 591 \\
\hline Zahedan & 60.9 & 29.5 & 1370 \\
\hline Saravan & 62.3 & 27.3 & 1195 \\
\hline Chabahar & 60.6 & 25.3 & 8 \\
\hline Rask & 61.4 & 26.2 & 500 \\
\hline Mirjave & 61.5 & 29.0 & 900 \\
\hline Nikashahr & 60.2 & 26.2 & 510 \\
\hline Sarbaz & 61.3 & 26.6 & 880 \\
\hline
\end{tabular}

\subsection{Methodologies}

The impact of a heat wave varies considerably from region to region. There is no universal definition of a heat wave. However, some authors agree that such events could include the exceedance of local threshold temperatures in the area of interest (Tan et al., 2007). A heat wave can be seen as an extended period of unusually high atmosphere-related heat stress, which causes temporary modifications in lifestyle (Robinson, 2001). There are various indices of heat waves, several definitions require the duration of above normal conditions for 2-3 days Definitions of heat waves generally comprise three components; a meteorological variable (often maximum temperature), a threshold for that variable, and duration. Threshold temperatures are either categorical, for example $30^{\circ} \mathrm{C}$, or relative, for example the 90th percentile (Karl \& Knight 1997). The duration of heat waves is typically taken between two and six days (Nasrallah, Nieplova \& Ramadan, 2004; Khaliq et al. 2007). All these indices and studies either explicitly or implicitly recognize the dilemma inherent in any quantification of the expectation of extremes: extreme events are by definition rare, and reliable quantification of their frequencies becomes more difficult as the events become more extreme with regard to threshold, duration or both. In this study we used daily maximum temperature to count the frequency of extended periods of extreme temperature. Extreme temperature is defined as a temperature above a daily percentile threshold to ensure that the heat wave index is applicable to different climatologically regions. Therefore, we developed and change this index for use in this study.

Using daily maximum temperature the 90th percentile of temperature was found for each station. A heat wave event occurred if it satisfied these criteria: maximum temperature 
$\geq 90$ th percentile of the maximum temperature for the month in which the heat wave begins for a minimum of 3 consecutive days (Table 2).

Table $2.90^{\text {th }}$ percentile of the maximum temperature for each station

\begin{tabular}{|l|l|l|l|l|l|}
\hline Zahak & Konarak & Zabol & Khash & Iranshahr & Zahedan \\
\hline 43.6 & 40 & 43.6 & 39 & 45.7 & 38.6 \\
\hline Saravan & Chabahar & Rask & Mirjaveh & Nikshahr & Sarbaz \\
\hline 40.8 & 44.2 & 44 & 44 & 44.9 & 42 \\
\hline
\end{tabular}

For this definitional study, the aim was to use long-term serially complete records for a large number of stations. Data from 12 stations (Fig. 2) for the 1961-2014 (19710 days) period were used, which are normally distributed throughout the province. In the next stage, using a database of maximum temperature, isothermal maps from 1961 to 2014 (Fig. 3) on the cell with dimensions of $15 \times 15 \mathrm{~km}$ using a rigorous geo-statistical technique (kriging), have been made.

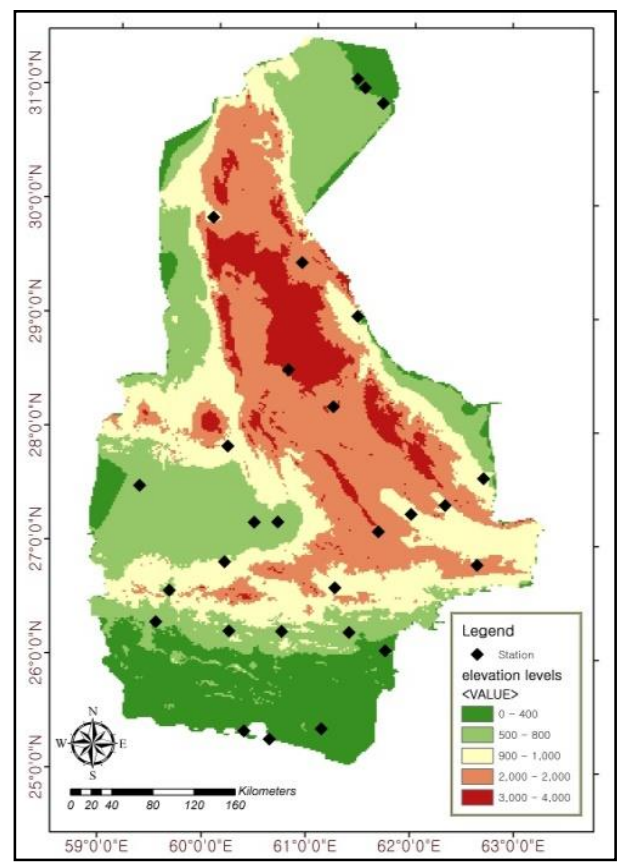

Fig. 2. Geographical location of meteorological Stations.

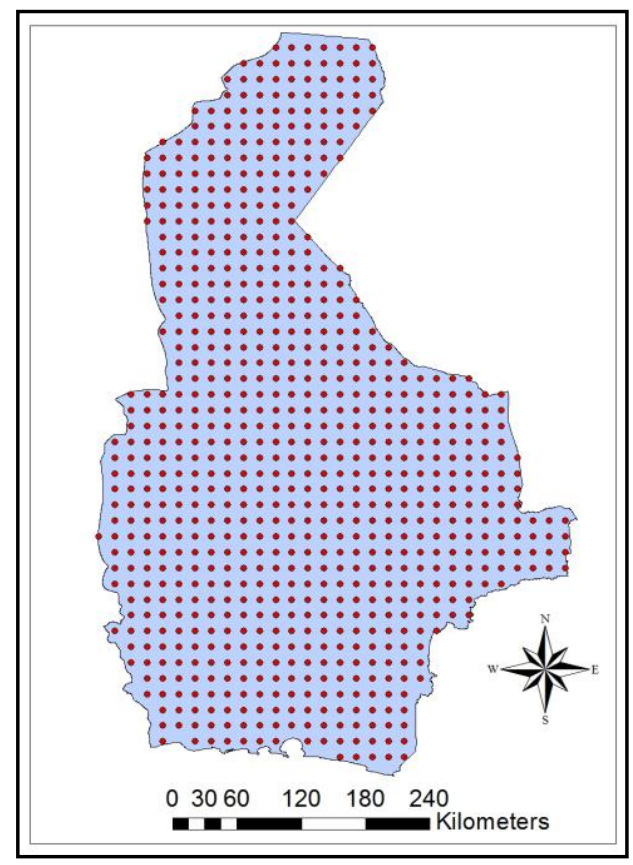

Fig. 3. Gridded heat waves surfaces, resolution $15 \mathrm{~km} \times 15 \mathrm{~km}$.

Kriging produces standard error estimates, and these can be used to assess the relative spatial accuracy of the identified trends (Funk and Verdin, 2009). Simple kriging is ordinary kriging with a known mean. Therefore it is slightly more powerful than ordinary kriging. For this process used ArcGIS 10.2 Software. GIS is an effective tool for data 
integration and spatial analysis (Rhind, 1991) With so much spatial variability in natural variables, such as heat, GIS provide convenient ways to comprehend, organize, and analyze the complexity of this spatial variation (Cohen, 2008). Using the results of these tools could enhance a Sistan and Baluchestan heat waves awareness to identification of heat waves behaviors.

\section{RESULTS AND DISCUSSION}

Heat waves are a fact of life. Heat waves are important disasters in many countries for death like other natural disasters. Every year in Sistan and Baluchestan province heat wave events (with Daily maximum temperatures $\geq 38^{\circ} \mathrm{C}$ ) usually occur over a span of several days. The Sistan and Baluchestan heat wave was sustained over June, July, September and August. People living in urban and rural areas are at risk from the effects of a prolonged heat wave. Sistan and Baluchestan Province is one of the 31 provinces of Iran. It is in the southeast of the country, bordering Pakistan and Afghanistan and its capital is Zahedan.

There are 10 cities in the province, Zahedan is the centre of province. The most important cities are Zabol and Zahak in the north and Khash, Iranshahr, Saravan, Sarbaz, Nikshahr, Chabahar and Konarak in the south. The area of the province is $187500 \mathrm{sq} \mathrm{km}$ $1600 \mathrm{~km}$ joint border with Pakistan and Afghanistan and $300 \mathrm{~km}$ water border on the coast of Oman Sea. It has a population of 2240000 people from different ethnic groups.

In the north Dasht- e- Sistan formed by Hirmand alluvium holds the largest fresh water lake of the world as well as Khaje Mountain. The 120-day winds are a distinguishing feature of this region. The southern part is mostly mountainous with a variety of climates due to the vicinity with Taftan Volcano and Oman Sea.

Many areas of society in Siatan and Baluchestan are more susceptible to the effects of heat waves. Sistan plain, Jazmurian district and south of province are susceptible. Unusually high summer temperatures raise power demand for air conditioning, increase heat stress on crops, and may create dangerous conditions for human health (Kalkstein, 1993). Episodes of extremely high temperatures, especially in conjunction with water shortage, can damage plants (Bassow, McConnaughay \& Bazzaz, 1994) in southern of Iran.

This index has been mapped to create a spatial representation of Maximum temperature $\geq$ 90th percentile (noticed as 90p) in the Station of Sistan and Baluchistan (Fig. 4).

The $90 \mathrm{p}$ value index provides an indication of the magnitude of maximum temperatures and heat waves. The climatology for the $90 \mathrm{p}$ value reflects the hotter temperatures in the central of Sistan and Baluchistan. The mean annual maximum temperature over Sistan and Baluchestan also showed the warming over most part of Sistan and Baluchistan. The maximum temperature was recorded having higher temperature over west province, Sistan, Pishin, and Iranshahr areas. In 2014, SB witnessed maximum extreme temperature to the tune of above $50^{\circ} \mathrm{C}$. The monthly mean temperature over the western and northern Sistan and baluchestan region was the highest in the last 60 years. This time frame was chosen so as to avoid the accelerated warming over the last sixteen years. Fig. 5 shows the behavior of extreme temperature events based on selected thresholds (90th percentile) in SB. The thresholds for Sistan plain and Iranshahr and Sarbaz district are $50,6^{\circ} \mathrm{C}$. This coverage was intersected with GIS grids to interpolate the mean surface maximum temperature. In areas with high densities of heat waves observations the kriging process has been well constrained and smooth variations in interpolated heat waves and rounded anomalies are typical. 


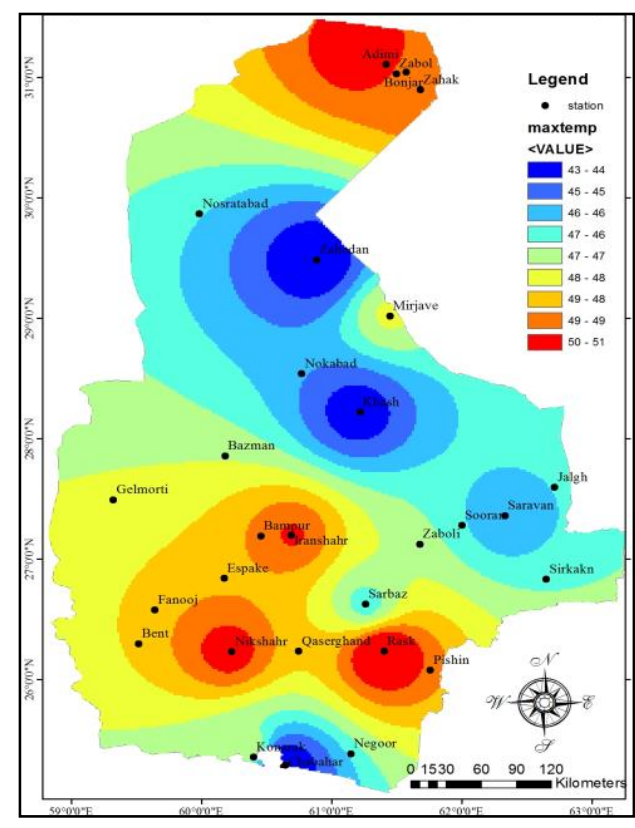

Fig. 4. Maximum temperature1961-2014.

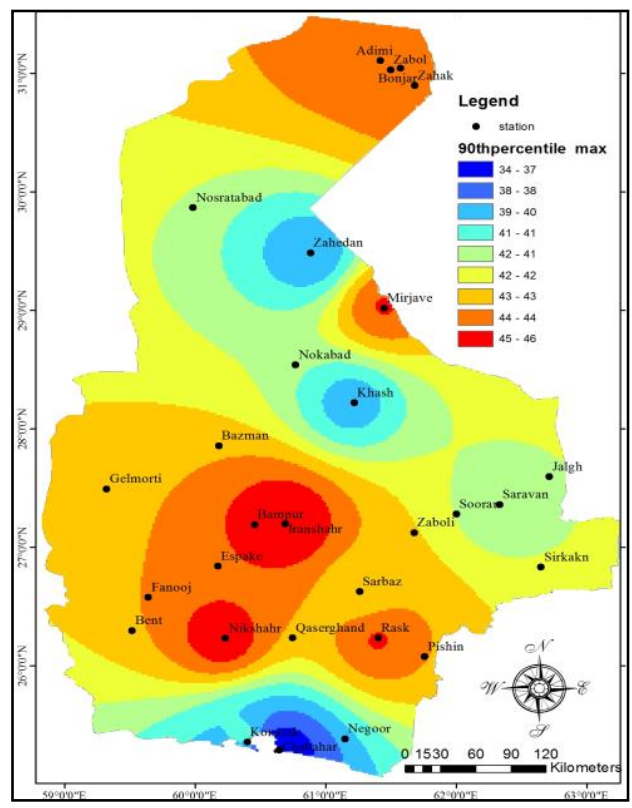

Fig. 5. $90^{\text {th }}$ percentile of the maximum temperature 1961-2014.

Heat stress conditions often occur in conjunction with dry spells or drought conditions (Jiang \& Huang, 2000). Over the Sistan and Iranshahr the occurrence of heat waves has been increased. The longest heat waves span approximately 9 to 15 days and the longest heat waves are in western regions SB. Heat waves are harder to sustain in western and southern SB due to the frequency of synoptic-scale systems passing through the regions. Stations with the maximum lower than $40^{\circ} \mathrm{C}$ are mainly located in the Taftan and Bazman Mountain and mountain areas in eastern SB (Fig. 6). Geographical distributions of the annual mean DMT exceeding the absolute and relative thresholds are compared.

The rising maximum temperature during the pre-monsoon months often continues till June, even in rare cases till July over the Southern areas in SB. Usually, This situation is exacerbated by increased humidity. Parts of the province in Sistan and Baluchestan, the heat waves during April to September led increasingly higher temperatures. The western Zahedan region was also warmer than normal during the March to October. The heat wave raised the maximum temperature above 9 to $11^{\circ} \mathrm{C}$.

The Hot Spot Analysis tool calculates the Getis-Ord Gi* statistic for each feature in a dataset. The resultant $\mathrm{z}$-scores and p-values tell you where features with either high or low values cluster spatially (Mitchell, 2005). The northern parts of Sistan and Baluchestan especially the Sistan plain regions and the Nosratabad plains are influenced by heat waves and hot days (Fig. 6). The output from the Hot Spot Analysis tool is a Z score and p-value for each feature. These values represent the statistical significance of the spatial clustering of values, given the conceptualization of spatial relationships and the scale of analysis

(Fig. 7). 
The higher (or lower) the $\mathrm{Z}$ score, shows the more intense the clustering, A $\mathrm{Z}$ score near zero means no spatial clustering.

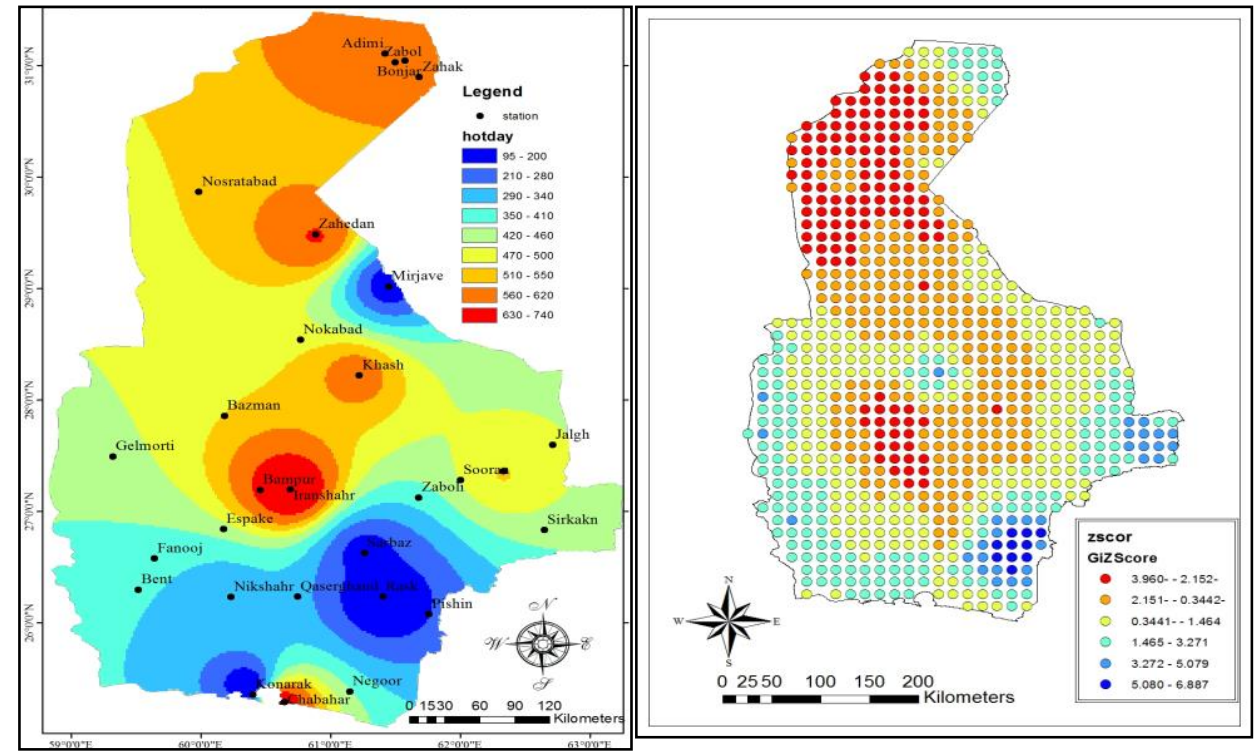

Fig.6. Hot day in Sistan and Baluchestan.

Fig.7. Hot spot in Sistan and Baluchesatan.

The pole of heat wave is Iranshahr with 740 heat waves in the period. The maximum numbers of heat waves occur in Iranshahr, Nikshar, Saravan and Zabol. In recent years the number of heat wave increased. These several States rank the highest in terms of casualties from heat wave. The reason for this could be the poor level of development and lack of shelters to the outdoor workers and farmers. West province of SB experienced most frequent heat wave, severe heat wave and highest number of heat wave, severe hot days during the decade 2005-2015.

There was a clear increase in the frequency of HWs after the 2005s in the Zabol region and west SB, compared to the period from the 1965s to 2000s (Table 3). The occurrence and persistence of the hot spell in July 2014 thus, appears to be an unique event in the 21 century. Notably the period roughly coincided with last two decades of the twentieth century which witnessed unprecedented high temperatures globally as a result of the global warming.

The trend of heat waves is shown in Fig. 8. The heat waves over Sistan and Baluchestan. Are also showed the warming over most parts of this Province. The heat waves were the occurrence of heat waves over west and North West of Sistan and Baluchestan such as Iranshahr, Jazmourian plain and Nosratabad. The heat waves were generated in these places and killed many people. 
Table 3. Number of heat waves over Sistan and Baluchesatan

\begin{tabular}{lccccc}
\hline \multicolumn{5}{c}{ Frequency of heat waves } \\
Station & $1965-1975$ & $1976-1985$ & $1986-1995$ & $1996-2005$ & $2006-2015$ \\
\hline Zahak & 85 & 69 & 88 & 104 & 123 \\
Konarak & 91 & 99 & 101 & 129 & 151 \\
Zabol & 95 & 105 & 119 & 132 & 167 \\
Khash & 27 & 29 & 49 & 65 & 87 \\
Iranshahr & 112 & 87 & 142 & 169 & 202 \\
Zahedan & 34 & 36 & 54 & 67 & 89 \\
Saravan & 94 & 97 & 121 & 159 & 179 \\
Chabahar & 92 & 102 & 101 & 131 & 126 \\
Rask & 97 & 113 & 123 & 148 & 159 \\
Mirjaveh & 41 & 39 & 67 & 78 & 96 \\
Nikshahr & 102 & 115 & 138 & 159 & 195 \\
Sarbaz & 100 & 120 & 134 & 156 & 171 \\
\hline
\end{tabular}

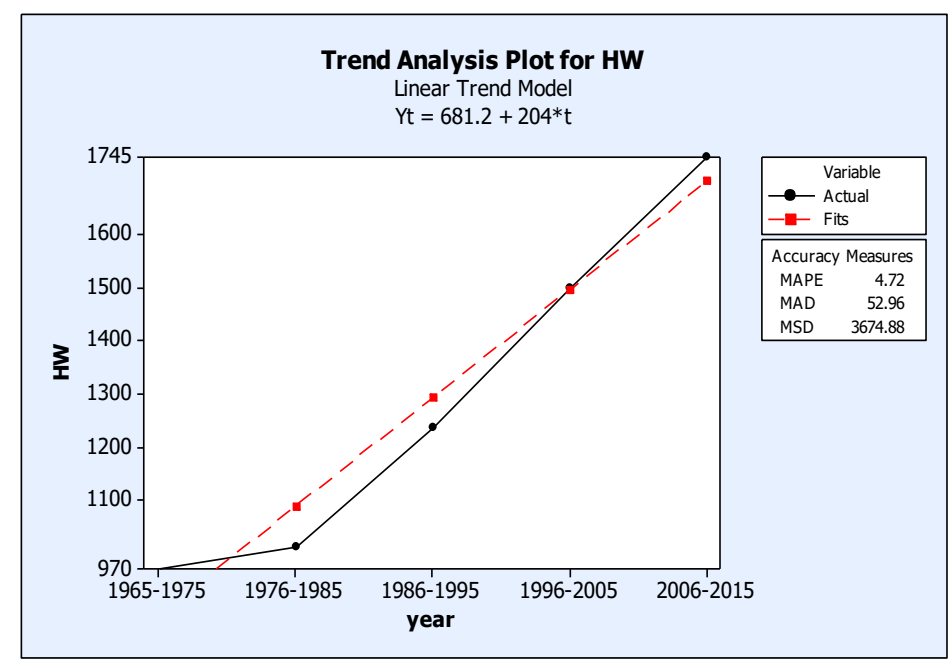

Fig. 8. Trend of heat waves in (The sum of heat waves for every period).

The frequency of heat waves were detected in stations than for spatial analysis of heat waves was to interpolate. High heat waves frequencies are evident over a large part of along the east coastal of Chabahar and Bahucalat in the corner of stoutest Sistan and Baluchestan (Fig. 9). Spatial patterns of changes are evident for the different return periods analyzed, but the percentage changes are even larger for the more extreme heat events. Over the west and south coasts and in the north-west, significant increases have been observed at a number of stations. 


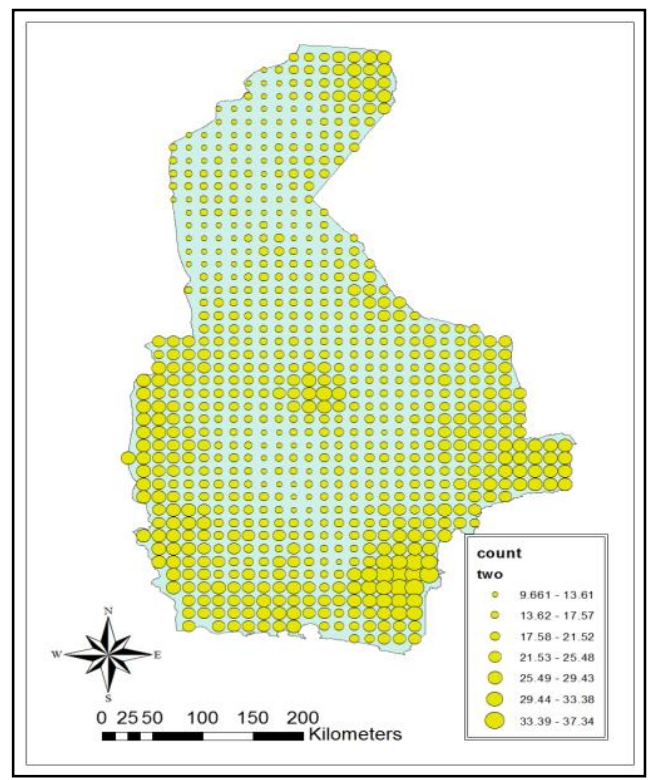

Fig. 9. Frequency of heat waves in Sisatan and Baluchestan.

In areas such as the Iranshar, Zabol and central part of the province where there is an increase in the intensity of heat wave. In recent years (2005-2015) heat waves events have occurred and have increase in intensity (Table 4). During hot summer water consumption increases drastically and often causing shortage of drinking water. Lack of water in most of the wells, pond, and tube well and other bodies during hot summer seasons, which has an adverse effect on human being and animal population.

Table 4. Statistics of maximum and hot days temperature ${ }^{\circ} \mathrm{C}$ in Sistan and Baluchestan province

\begin{tabular}{lccc}
\hline Station & N hot days & Max Temp & Mean Max Temp \\
\hline Zahak & 590 & 49 & 43.5 \\
Konarak & 114 & 47 & 41.9 \\
Zabol & 584 & 49.6 & 44.9 \\
Khash & 583 & 43.4 & 39.9 \\
Iranshar & 744 & 49.2 & 46.6 \\
Zahedan & 629 & 43 & 39.8 \\
Saravan & 506 & 45.3 & 41.7 \\
Chabahar & 701 & 42.6 & 35.2 \\
Rask & 95 & 50.6 & 46.4 \\
Mirjave & 157 & 47.2 & 44.8 \\
Nikashahr & 303 & 49.6 & 45.6 \\
Sarbaz & 167 & 46 & 42.8 \\
\hline
\end{tabular}




\section{CONCLUSION}

The aim of this work is to study heat waves (HWs) in Sistan and Baluchestan (SB), because numerous deaths have been reported in this region, which are caused by heatstroke. Heat waves have been a part of extreme weather events, which cause enormous losses in Terms of lives and human discomfort and ailments arising out of them. This study describes the main characteristics of a heat wave that occurred over Sistan and Baluchestan province. Southern Iran is expected to find itself in a situation particularly compromising in a near future, threat from both heatwaves and the reduction of water resources. Because of the loss of life, damage to crops and vegetation in general and the impact on water supplies, these recent heat waves have stimulated much interest in their climatological features, recurrence times, and, especially, whether they are a portent of greenhouse induced climatic change. Over much of the province, there is significant evidence of increases in the intensity of heat waves events between 2005-2015. In parts of the northwest, Jazmourian plain, Cahbahar and Bahucalat region, increases in heat waves event have occurred since the late-2000. During the last 53 years, the number of heat waves in SB increased by 33 HWs per year, with a slight increase winter average temperature. The present analysis suggested that in the last recent winters the HWs increased over SB.in fact, cold period became shorter in the SB and significant positive trends in the frequencies of the HWs prevailed in most of Sistan and Baluchestan.

\section{References}

Bassow, S.L., McConnaughay, K.D.M. \& Bazzaz, F.A. (1994) The response of temperate tree seedlings grown in elevated $\mathrm{CO} 2$ to extreme temperature events. Ecological Applications, 4 (4), 593-603.

Changnon, S. A., Kunkel, K. E. \& Reinke, B. C. (1996) Impacts and responses to the 1995 Heat Wave: A call to action. Bulletin of the American Meteorological Society, 77, 1497-1506.

Cohen, A. (2008) Montana severe weather climatology using geographic information system and google earth, NOAA/NWS Great Falls, MT.

Della-Marta, P.M., Luterbacher, J., Von Weissenflush, H., Xoplaki, E., Brunet, M., \& Wanner, H. (2007) Summer heat waves over western Europe 1880-2003, their relationship to large scale forcing and predictability. Climate Dynamics (in press), Doi: 10.1007/s00382-007-0233-1.

Easterling, D. R., Meehl, G. A., Parmesan, C., Changnon, S.A., Karl, T. R., \& Mearns, L. O. (2000) Climate extremes: Observations, modeling, and impacts. Science, 289, 2068-2074.

Ebi, L.K., Meehl, A.G., (2007) Heatwaves \& global climate change. The heat is on: climate change \& heatwaves in the Midwest. Pew Center on Global Climate Change, Arlington, 14.

Fang, X.Q., Wang, A.Y., Fong, S.K., Lin, W.S., Liu, J. (2008) Changes of reanalysis-derived Northern Hemisphere summer warm extreme indices during 1948 - 2006 and links with climate variability. Global and Planetary Change, 63, 67-78.

Funk, C., \& Verdin, J.P., (2009) Real-time decision support systems-The famine early warning system network, in Gebremichael, M., and Hossain, F., eds., Satellite rainfall applications for surface hydrology: Netherlands, Springer, 295-320.

Goklany, I. (2008) Deaths and death rates from extreme weather events: 1900-2008. Journal of American Physicians and Surgeons, 14 (4), 102-09.

Hassid, S., Santamouris, M., Papanikolaou, N., Linardi, A., Klitsikas, N., Georgakis, C., \& Assimakopoulos, D.N. (2000) The effect of the Athens heat island on air conditioning load. Energy and Buildings, 32, 131-141. 
Huth, R., Kysely, J., Pokorna, L. (2000) A GCM simulation of heat waves, dry spells, and their relationships to circulation. Climate Change, 46, 29-60.

Jiang, Y. \& Huang, B. (2000) Effects of drought or heat stress alone and in combination on Kentucky. Crop Science, 40, 1358-1362

Kalkstein, L.S. (1993) Health and climate change-direct Impacts in cities. Lancet, 342, 1397-1399.

Karl, T.R. \& Knight, R.W. (1997) The 1995 Chicago heat wave: How likely is a recurrence? Bulletin of the American Meteorological Society, 78, 1107-119.

Khaliq, M.N., Gachon, P., St-Hilaire, A., Ouarada, T.B.M.J. \& Bobee, B. (2007) Southern Quebec (Canada) summer-season heat spells over the 1941-2000 period: an assessment of observed changes. Theoretical and Applied Climatology, 88, 83-101.

Kovats, R.S., \& Koppe, C. (2005) Heatwaves past and future impacts on health, in Integration of Public Health with Adaptation to Climate Change: Lessons learned and New Directions. Taylor and Francis, 136- 160.

Kyselý, J. (2004) Mortality and displaced mortality Turing heat waves in the Czech Republic. International Journal of Biometeorol, 49, 91-97.

Mitchell, A. (2005) The ESRI Guide to GIS Analysis. ESRI Press, 2.

McCarthy, J., Canziani, O., Leary, N., Dokken, D. \& White, K. (2001) Climate Change 2001: Impacts, Adaptation, and Vulnerability. Cambridge Univiversity Press, 1032.

McGeehin, M. A. \& Mirabelli, M. (2001) The potential impacts of climate variability and change on temperature related morbidity and mortality in the United States. Environmental Health Perspectives, 109, 185-89.

McGregor, G. R., C. A. T. Ferro, and D. B. Stephenson, (2005) Projected changes in extreme weather and climate events in Europe. Extreme Weather Events and Public Health Responses, Springer, New York, 13-23.

Meehl, G.A., Tebaldi, C., (2004) More intense, more frequent, and longer lasting heat waves in the 21st century. Science, 305, 994-997.

Nasrallah, H. A., Nieplova, E. \& Ramadan, E. (2004) Warm season extreme temperature events in Kuwait. Journal of Arid Environments, 58, 357-71.

Palecki, M. A., Changnon, S.A., \& Kunkel, K.E. (2001) The Nature and Impacts of the July 1999 Heat Wave in the Midwestern United States: Learning from the Lessons of 1995. Bulletin of the American Meteorological Society, 82, 1353-1367.

Rhind, D., (1991) Geographic information systems and environmental problems. International Social Science Journal, 43, 649-668.

Robine, J.M. Cheung, S.L., Le Roy, S., Van Oyen, H., Griffiths, C., Michel, J.P., Herrmann, F.R. (2008) Death toll exceeded 70,000 in Europe during the summer of 2003. Comptes Rendus Biologies, 331 (2), 171-178

Robinson, P.J., (2001) On the definition of a heat wave. Journal of Applied Meteorology, 40 (4), 762 75.

Schar, C., Vidale, P.L., Luthi, D., Frei, C., Haberli, C., Liniger, M.A., Appenzeller, C. (2004) The role of increasing temperature variability in European summer heatwaves. Nature 427, 6972, 332-336.

Stott, P., Stone, D., Allen, M, (2004) Human contribution to the European heatwave of 2003. Nature ,432, 610-614.

Tan, J., Youfei, Z., Song, G., Kalkstein, L.S., Kalkstein, A.J., Tang, X. (2007) Heat wave impacts on mortality in Shangai, 1998 and 2003. International Journal Biometeorology, 51, 193-200.

***IPCC, I. P. o. C. C. (2007). Climate Change 2007: Synthesis Report; Summary for Policymakers. 